INNOVATIVE CLEAN COAL TECHNOLOGY (ICCT)

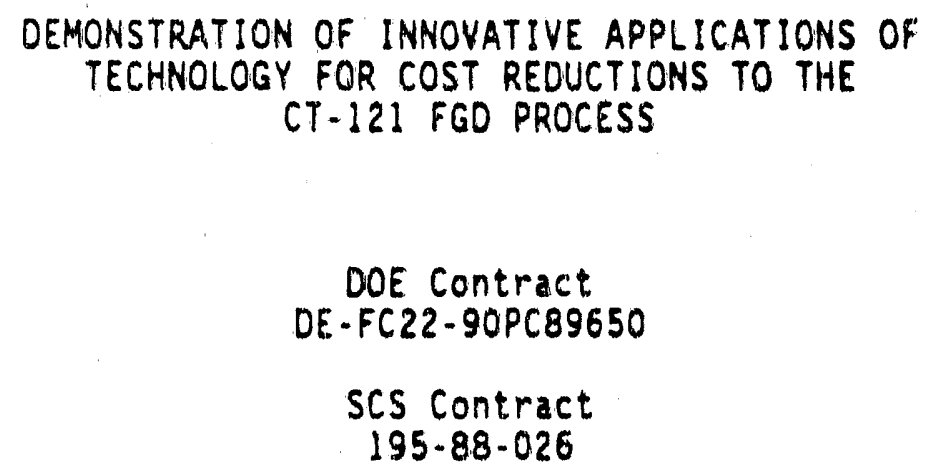

November 15,1990

Prepared by:

Southern Company Services, Inc.

800 Shades Creek Parkway

Birmingham, Alabama 35209

Patents Cleared by Chicago on $11 / 17.1990$ 
This report was prepared by Southern company Services, Inc. pursuant to a cooperative agreement partialiy funded by the U.S. Department of Energy and neither Southern Company Services, Inc. nor any of its subcontractors nor the U.S. Department of Energy, nor any person acting on behalf of either:

(a) Makes any warranty or representation, express or implied with respect to the accuracy, completeness, or usefuiness of the information contatned in this report, or that the use of any information, apparatus, method, or process disclosed in this report may not infringe privately-owned rights; or

(b) Assumes any liabilities with respect to the use of, or for damages resulting from the use of, any information, apparatus, method or process disclosed in this report.

Reference herein to any specific comercial product, process, or service by trade name, trademark, manufacturer, or otherwise, does not necessarily constitute or imply its endorsement. recommendation, or favoring by the U.S. Department of Energy. The views and opinion of authors expressed herein do not necessarily state or reflect those of the U.S. Department of Energy. 
Section 1

SUMMARY

The objective of this project is to demonstrate on a commercial scale several innovative applications of cost-reducing technology to the chiyoda Thoroughbred-121 (CT-121) process. CT-121 is a second generation flue gas desulfurization (FGD) process which is considered by the Electric Power Research Institute (EPRI) and Southern Company Services (SCS) to be one of the most reliable and lowest cost FGD options for high-sulfur coal-fired utility boiler applications. Demonstrations of the following innovative design approaches will further reduce the cost and provide a clear advantage to $\mathrm{CT}$ 121 relative to competing technology:

- use of fiberglass reinforced plastir (FRP) to construct the absorber vessel, wet ducts, and chimney (stack),

- elimination of flue gas reheat,

- elimination of the need for a spare absorber, and

- use of a single vessel to obtain simultaneous particulate and $\mathrm{SO}_{2}$ removal.

The demonstration will be performed at Georgia Power Company's Plant Yates Unit No. 1 (100 MW capacity) near Newnan, Georgia. The project will be funded by the U. S. Department of Energy (DOE), SCS (on behalf of the entire southern electric system), and EPRI. SCS is the participant responsible for manaing all aspects of this project.

The project is being conducted in the following three phases:

Phase I - Permitting and Preliminary Engineering;

Phase II - Detailed Engineering, Construction, and Startup; and

Phase III - Operation, Testing, and Disposition.

During the July-September 1990 quarter, activities in both Phase I and Phase II were continued. In Phase I, permitting activities were continued by toth SCS and Georgia Power to obtain air and gypsum disposal permits. Work on the Environmental Monitoring Plan continued based on the Environmental Monitoring Plan Outline submitted during the pre-award period. An initial set of groundwater samples were obtained from the gypsum stack site. Conceptual process engineering activities were substantially completed with agreement between Chiyoda and SCS on several issues. Detailed engineering activities included developinent of specifications, inquiry packages, evaluation of bids, and award of contracts in several areas. Detailed design of the FRP vessels (JBR, prescrubber, and limestone storage tank) was begun by SCS and Ershigs. Georgia Power Company Construction Management personnel began to set up for construction at Plant Yates. A groundbreaking ceremony was conducted at Plant 
Yates in August, and an initial project review meeting with DOE and EPRI was conducted at that time. 
Section 2

INTROOUCTION

The Innovative Clean Coal Technology (ICCT) Program is designed to demonstrate clean coal technologies that are capable of retrofitting or repowering existing facilities to achieve significalt reduction in sulfur dioxide $\left(\mathrm{SO}_{2}\right)$ and/or nitrogen oxides (NOX) emissions. The technologies selected for demonstration are capable of being commercialized in the $1990 \mathrm{~s}$ and are expected to be more cost effective than current technologies.

This ICCT project is jointly funded by the U.S. Department of Energy, the Electric Power Research Institute (EPRI), and by Southern Company Services (SCS) on behalf of the entire Southern electric system. The project's objective is to demonstrate innovative applications of technology for cost reduction for the Chiyoda Thoroughbred-12! (CT-121) process. The CT-121 process is a second generation fiue gas desulfurization (FGD) process that EPRI and SCS consider to be one of the least cost FGD processes in its current commercial configuration. Further cost reductions will only make this process more competitive and attractive to electric utilities.

The CT-121 process is a wet $F G D$ process that removes $\mathrm{SO}_{3}$, can achieve simultaneous particulate control, and can produce a salable by-product gypsum thereby eliminating solid waste production. Figure 1 shows a flow schematic of the process. CT-121 removes $\mathrm{SO}_{2}$ and particulate matter in a unique limestone-based scrubber called the Jet Bubbling Reactor (JBR). In the JBR, flue gas bubbles beneath the slurry, $\mathrm{SO}_{2}$ is absorbed, and particulate matter is removed from the gas. The agitator circulates slurry to ensure that fresh slurry is always available in the bubbling or froth zone so that $\mathrm{SO}_{2}$ removal can proceed at a rapid rate. Air is introduced into the bottom of the JBR to oxidize the absorbed $\mathrm{SO}_{2}$ to sulfate, and limestone is added to neutralize the acid slurry and form gypsum. The JBR is designed to allow time for complete oxidation of the $\mathrm{SO}_{3}$, for complete reaction of the limestone, and for growth of large gypsum crystals. The gypsum siurry is continuously withdrawn from the IBR and can be dewatered in a gypsum stack. The stacking technique involves filling a diked area with gypsum slurry, allowing the gypsum solids to settle, and removing clear liquid from the top of the stack and returning it to the process.

ine $61-121$ process is in commercial use in Japan and in the United States. At the University of 111 inois, a $45 \mathrm{MW}$ process began operations in 1988 on a stoker boiler, which is not a typical utility boiler. In Japan, commercial CT-121 processes are used to treat the flue gas from bollers which burn oil or low-sulfur coal. Some of the Dil-fired units do not include particulate control devices upstream of the $\mathrm{CT}-121$ processes.

The purpose of this ICCT project is to demonstrate the process on highash and high-sulfur U.S. coal using several design modifications that will reduce the estimated cost of the present $C T-121$ process by 23 percent for 


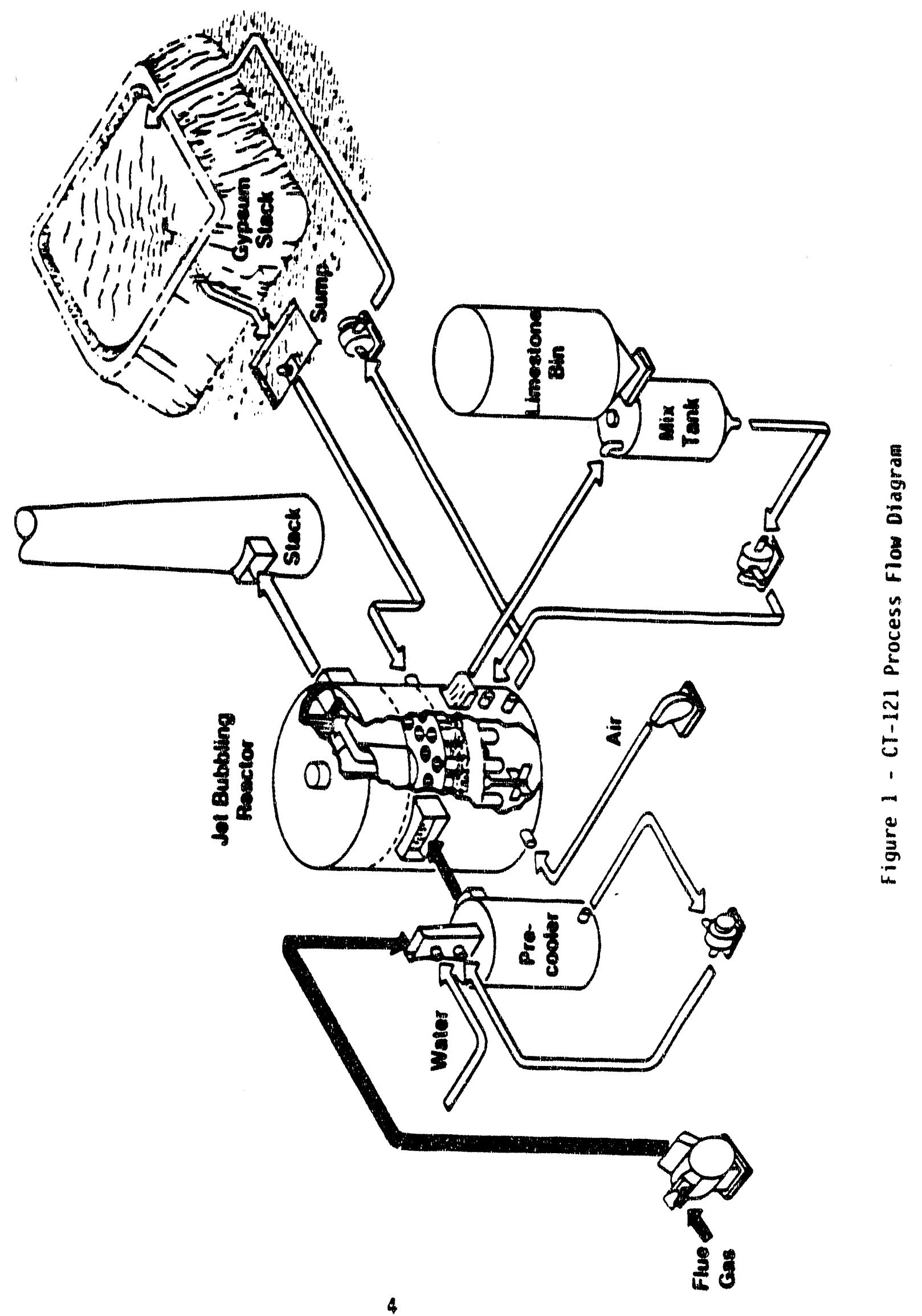


power plant retrofit applications and 50 percent for new power plant installations. This will be accomplished while maintaining 90 percent $\mathrm{SO}_{2}$ removal and high particulate removal efficiency. A reusable gypsum byproduct will also be produced during the project.

The Major cost-reducing design changes to be demonstrated are:

- using less expensive materials of construction,

- eliminating a spare absorber module,

- eliminating flue gas reheat, and

- combining $\mathrm{SO}_{2}$ and particulate removal in a single vessel.

Utility scale units with the CT-12l processes currently include a prescrubber for control of soluble chloride concentration and use JBRs made of stainless steel, which is relatively expensive. Typically, outlet ducis are lined or made of alloys, and the chimney is lined. Liners have to be replaced after a period of time which adds additional expense and inconvenience. For this demonstration project, the prescrubber, JBR, outlet duct, and chimney will be made of solid fiberglass-reinforced plastic (FRP) which is unaffected by chloride or other corrosion mechanisms normally experienced in FGD processes. A successful demonstration of FRP in this project will eliminate the need for a prescrubber in the CT-121 process and will demonstrate a material which is 1 ess expensive that $316 \mathrm{~L}$ stainless steel.

Current Federal New Source Perforinance Standards (NSPS) require that spare scrubbers normally be installed on utility FGO systems. This project is intended to demonstrate that the $C T-121$ process using a JBR made of FRP is highiy reliable and does not require a spare absorber module to effectively control $\mathrm{SO}_{2}$ emissions.

Another cost-saving modification to be demonstrated in this project is the elimination of fiue gas reheat downstream of the scrubber. The flue gas leaving any scrubber is at its water dewpoint, and, without reheat, subsequent cooling in the ductwork and stack causes moisture to condense into small droplets. These water droplets absorb traces of $\mathrm{SO}_{2}$ and form acid droplets that cause severe corrosion in ducts and stacks. In addition, these droplets tend to fall near the base of the stack, causing damage to surrounding structures and vehicles. To prevent these problems, this project will use operating techniques and equipment designs that will eliminate the need for costly reheating.

The final cost-saving modification is simultaneous removal of $\mathrm{SO}_{2}$ and particulate matter in the JBR. Typically, an electrostatic precipitator or fabric filter is used upstream of the scrubber to remove particulate matter. In the CT-121 process, greater than 90 percent of the $\mathrm{SO}_{2}$ and 99 percent of the particulate matter in the entering flue gas can be removed in the JBR. When used in new power plants, the el imination of the ESP or fabric filter will result in substantial capital and operating cost reductions. Thus, the $C T-121$ process provides a cost effective alternative to conventional wet $F G D$ systems. 
This project will be performed at Georgia Power Company's Plant Yates, Unit No. 1. This plant is located about 40 miles southwest of Atlanta near Newnan and Carrollion. The CT-121 process to be installed for this demonstration project will treat the whole flue gas stream generated by the $100 \mathrm{MW}$ Unit 1 boiler. The coal to be burned during the project will be a blend of Illinois 5 and 6 coals and will contain between 2.5 and 3 percent sulfur coal.

The demonstration project will be conducted over an 81 -month period with project activities including environmental monitoring, permitting, design, construction, operation, process evaluation, and gypsum by-product evaluation. The project is organized into three phases: (1) Phase I - Permitting and Preliminary Engineering; (2) Phase II - Detailed Engineering, Construction, and Startup; and (3) Phase III - Operation, Testing, and Disposition. Phase I is scheduled for 8 months, Phase II is scheduled for 27 months with a sixmonth overlap with Phase I, and Phase III is scheduled for 52 months. Operations are planned for 24 months with the remainder of Phase III activities dedicated to gypsum byproduct utilization and gypsum stack groundwater monitoring studies. The cooperative agreement was signed April 2, 1990 , and the project completion date is projected to be mid-1996. The total estimated project costs are $\$ 35,843,678$. The co-funders are SCS $(\$ 11,297,032), \operatorname{DOE}(\$ 17,546,646)$, and EPRI $(\$ 7,000,000)$. 


\section{Section 3}

\section{PROJECT DESCRIPTION}

Within the three phases of the project, the following tasks will be conducted to effectively demonstrate a reduced-cost $\mathrm{CT}-121$ process:

\footnotetext{
Phase I - Permitting and Preliminary Engineering

Task 1 - Development of Environmental Monitoring Program

Task ? - Permitting Activities

Task - Preliminary Engineering

Task 4 - Gypsum Stack Site Characterization and Groundwater Well Siting Activities

Task 5 - Process Engineering Support

Task 6 - Georgia Power Engineering Coordination

Task 7 - Project Management and Reporting

Task 8 - Preliminary Gypsum Stacking and Byproduct Studies

Phase II - Detailed Design, Construction, and Startup

Task 1 - Detailed Design Engineering

Task 2 - Process Engineering Support

Task 3 - Georgia Power Engineering Coordination

Task 4 - Construction

Task 5 - Test Plan Development

Task 6 - Training of Operations and Maintenance

Personnel

Task 7 - Startup

Task 8 - Baseline Groundwater Monitoring

Task 9 - Environmental Data Management and

Reporting

Task 10 - Project Management and Reporting

Task 11 - Phase II Gypsum Stack Design and Byproduct Studies

Phase III - Operations, Testing, and Disposition

Task 1. Operations and Maintenance

Task 2 - Process Evaluation

Task 3. Gypsum Stacking and Byproduct Evaluation

Task 4 - Groundwater Monitoring

Task 5 - Environmental Data Management and Reporting

Task 6 - Economic Analysis

Task 7 - Disposition

Task 8 - Project Management and Reporting
} 


\section{Section 4}

\section{PROJECT STATUS}

Progress during the July-September 1991, quarter is summarized below. Most of the activities were in the environmental and engineering tasks.

\section{PHASE I - PERMITTING AND PRELIMINARY ENGINEERING}

\section{Task 1 - Development of Environmental Monitoring Program}

An initial draft of the Environmental Monitoring Plan was developed by Radian and reviewed by SCS during the quarter. This draft $p$ lan includes a quality assurance/quality control project plan and sampling and analyses procedures manual. Revisions will be made so that the EMP can be submitted to DOE during the next quarter.

\section{Task2 - Permitting Activities}

The permits required for the project are in three categories: (1) those required during construction, (2) air permits required for operation, and (3) water permits for operation of the process and the gypsum stack. Georgia Power and SCS have continued efforts in all three areas. Information regarding emissions during construction has been collected from the fiberglass manufacturer, and initial discussions have been held with the state. The State of Georgia has formally agreed that no air permit is required for fiberglass construction activities. The fiberglass manufacturer will be responsible for disposal of any solid waste which is categorized as hazardous.

Georgia Power and SCS also continued work on the air permit application required for operations. An application was prepared and submitted to the Georgia Environmental Protection Division for approval. The State responded with some a request for addition information and clarification.

Work on the gypsum stack permit also continued. A geotechnical report of the gypsum site was completed (see Task 4) and initial conversations were held with the state regarding liner requirements. A formal permit application including the design and operating plan is expected to be submitted in the next quarter.

\section{Task 3 - Preliminary Engineering and Task 5 - Process Engineering Support}

Conceptual process engineering continued during the period. A meeting was held in August with Chiyoda to resolve several key process issues. Based on the results of this meeting, the process flow diagram, plant layout drawing, and general arrangement drawings were revised. The major activity remaining in preliminary engineering is the development of a system design basis document which is expected to be completed in the next quarter. 
Ij:! $:$ - Gyosum Stack Site Characterization and Groundwater Well siting Activities

Activities to support the gypsum stack permitting effort were continued during the quarter. A geotechnical report was completed and sent to Georgia Power Company for inclusion in the permit application. Groundwater wells were installed at five locations around the gypsum stack site.

\section{Iask 6 - Georgia Power Engineering Coordination}

A number of meetings have been held between SCS and Georgia Power Construction and Plant personnel. Frequent conversations between the lead discipline engineers at SCS and plant engineering staff have been conducted to ensure that the plant perspective has been considered in engineering and procurement decisions.

\section{Task 7 - Project Management and Reporting}

The management information system continues to be used to control budget and schedule and to help fulfill DOE reporting requirements. Monthly reports have been submitted. Weekly meeting with lead engineers and construction management and monthly project review meetings were conducted. Negotiations with Ershigs continued for the FRP manufacturing contract. A letter agreement with Ershigs was signed to maintain the project schedule. Final negotiations for the FRP contract are expected to be concluded in December, 1990 .

\section{Task 8 - Preliminary Gyosum Stacking and Byoroduct Studies}

In this task, SCS has coordinated with Ardaman and Associates to collect site and laboratory data required to perform gypsum stack design calculations. Clay, local to the Plant Yates site, has been evaluated for its potential use as a gypsum stack liner material. Based on the options available, a synthetic liner will be proposed for the Yates gypsum stack site.

Preliminary agricultural studies with gypsum from other FGD sites in the United States continued at the University of Georgia. Additional gypsum samples from the University of IIIinois CT-121 process were shipped to the University of Georgia. The results of these preliminary tests will be used to complete final test plans for the agricultural studies with the Plant Yates CT in: gjojisum.

PHASE II - DETAILED DESIGN, CONSTRUCTION, AND STARTUP

\section{Task 1 - Detailed Engineering, Task 2 - Process Engineering Support, and Iask 3 - Georgia Power Engineering Coordination}

The engineering schedule continues to be highly integrated with a number of activities close to the critical path. Thus far, the changes required in schedule in engineering and construction have not affected the May 1992 startup date. The following summarize progress in the detailed engineering task: 
- Evaluated bids and awarded contracts for the scrubber control bullding, fan, fan motor, limestone ball mill system. $115 \mathrm{kV}$ transformer, $4160 \mathrm{~V}$ and $480 \mathrm{~V}$ motor control centers and switchgear. A contract was negotiated for $4160 \mathrm{~V} / 480 \mathrm{~V}$ power transformer pending final resolution of terms and conditions.

- Developed specifications and sent inquiry packages to vendors for the limestone storage and transfer system, plant air compressor, and digital data acquisition and control system.

- Began development of specifications for the oxidation air blowers, continuous emissions monitoring system, vertical pumps, horizontal pumps, and agitators.

- Held weekly meetings among Civil, Electrical, I\&C, Mechanical, and Process Engineering Disciplines to facilitate communications. Weekly conference calls were held with the Construction Manager. Monthly Project review meetings were held at Plant Yates.

- Continued design of FRP vessels with Ershigs.

- Began foundation design for JBR, prescrubber, limestone storage tank, and chimney.

\section{Task 4 - Construction}

Construction site activities were begun with the set up of construction management offices. A new parking lot was completed since one of the existing lots is being used in the CT-121 process. Construction activities shouid increase significantly next quarter.

\section{Task 8 - Baseline Groundwater Monitoring}

An initial set of groundwater samples were collected in September from the wells around the gypsum stack site. Analyses of these samples were begun. Additional sets of samples are planned every two months for the next year. 

Section 5

PLANNED ACTIVITIES planned:

During the October - December 1990 quarter, the following activities are

- Continue permitting activities. Clarify questions concerning the ir permil. Complete gypsum stack design, prepare design and operating plan, and submit gypsum stack permit to State of Georgia.

- Submit Environmental Monitoring Plan to DOE. Include a Sainpling and Analys is Manual and a Quality Assurance/Quality Control Plan.

- Write the system design basis document.

- Award limestone pulverizer system, fan, fan motor, control building, $115 \mathrm{kV}$ transformer, $4160 \mathrm{~V}$ and $480 \mathrm{~V}$ motor control centers, $4160 \mathrm{~V} / 480 \mathrm{~V}$ power transformer, and $4160 \mathrm{~V}$ and $480 \mathrm{~V}$ swit.chgear.

- Finalize contract with Ershigs for FRP equiphent. Approve required drawings so that construction can begin.

- Complete specifications for steel ductwork and seructural steel and issue inquiry package.

- Complete development of specifications, issue inquiry packages receive and evaluate bios, and award contracts for the oxidation air blowers, continuous emissions monitoring system, vertical pumps, horizontal pumps, dampers and agltators.

- Evaluate bid and award contract for data acquisition and plant control systems.

- Complete specification, issue inquiry package to vendors, recelve and evaluate bids and award contract for continuous emissions monitoring system.

- Complete bid evaluations and award contract for limestone storage and iransfer system.

- Pour temporary foundation and mobilize for FRP manufacturing. Begin winding of JBR.

- Construct scrubber butloing foundation and begin construction of $J 6 R$ and prescrubber foundations. 

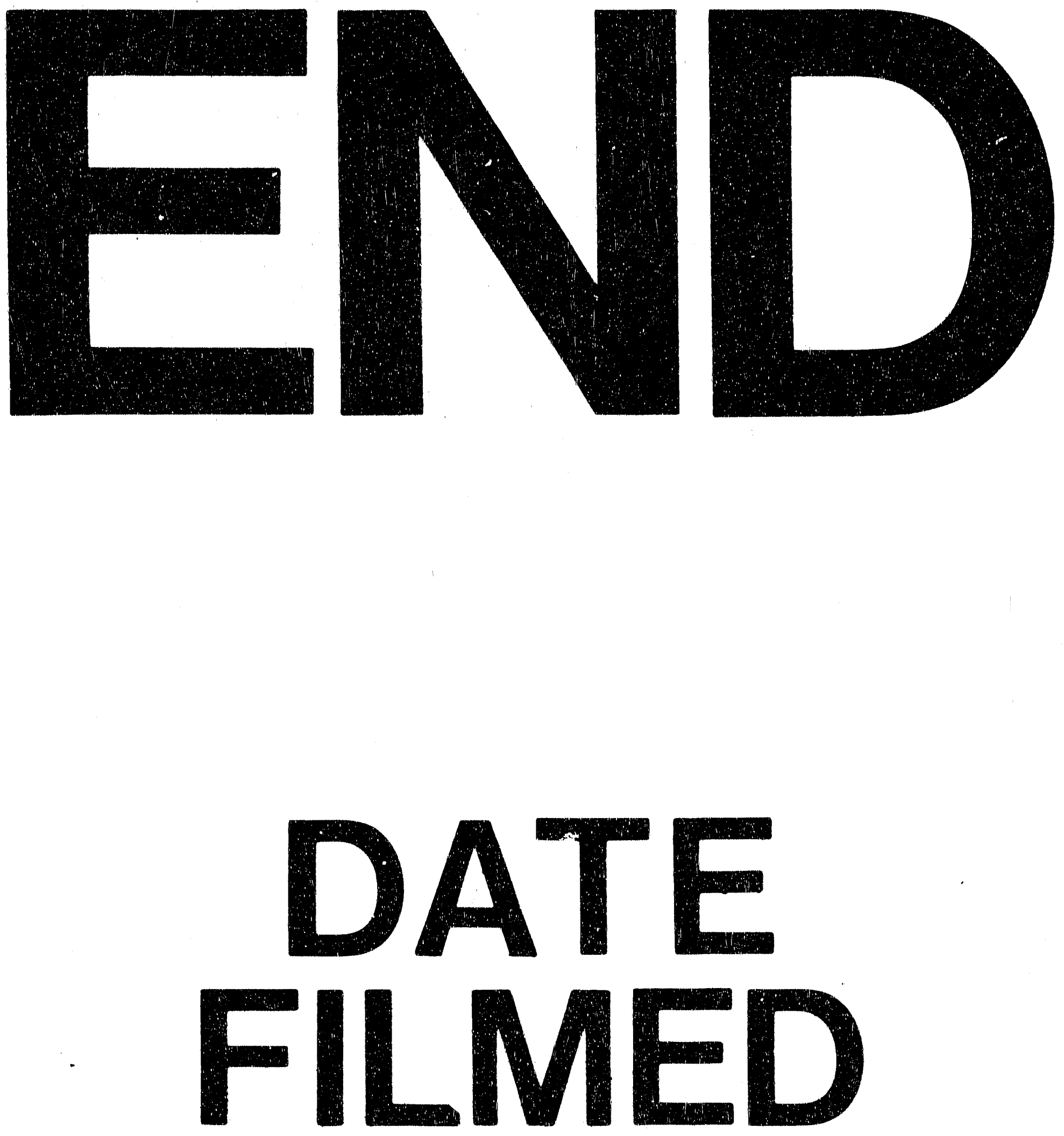

1

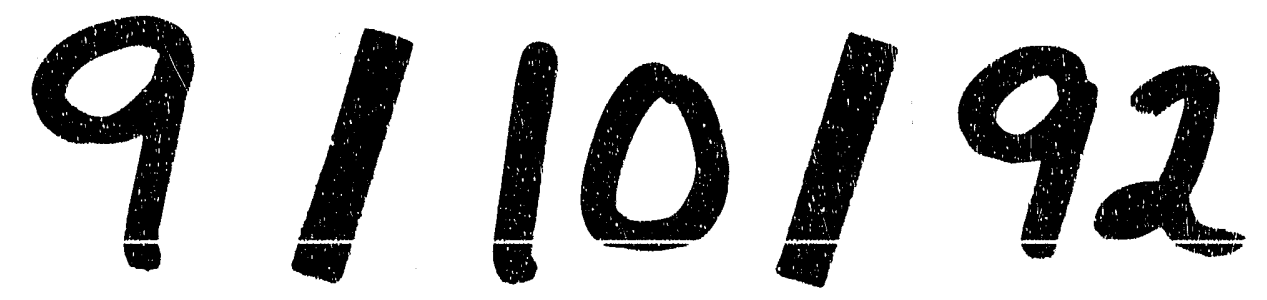


